\title{
Adopting a currency overlay programme: The French Pensions Reserve Fund experience
}

Received: 12th October, 2005

\section{Christophe Morel}

is currently Head of Research and Tactical Asset Allocation in the French Pensions Reserve Fund. He holds a PhD in Finance. He is also attached to the Paris-Dauphine University (CEREG) in Paris.

\begin{abstract}
This paper provides a background to implementing a currency overlay programme in a pension fund, through the French Pensions Reserve Fund (FRR) experience. The paper addresses two particular topics. First, it describes how a pension fund needs a 'currency philosophy' (on dynamic returns, forex market mechanism etc), as it necessarily deals with the governance issue. Secondly, the paper reports the FRR's currency overlay practice, even though it is obviously a work in progress.
\end{abstract}

Keywords: currency overlay, pension fund, risk management

\section{Introduction}

Due to demographic challenges and deficit projections, the French Government decided in 1999 to establish the French Pensions Reserve Fund (FRR). This is a pure reserve fund, a 'smoothing mechanism' which aims to set aside and invest significant financial resources until 2020, making the accrued resources gradually available thereafter to eligible plans, in particular the basic mandatory retirement plan set up for wage earners in the private sector. By limiting future increases in system contributions from active workers and their employers, the FRR contribution is intended, over time and between generations, to improve the distribution of input required to ensure the long-term financial equilibrium of such plans.

The FRR became operational in 2003. As of 30th June, 2005 the FRR total assets amounted $€ 23$.4bn with
$€ 5.1 \mathrm{bn}$ in international assets. To minimise risk through optimal diversification, the Fund is investing part of its resources in securities issued or traded outside the euro zone. As such, it is supposed to have a currency policy.

However, currency risk management is a delicate subject for a supervisory and executive pension fund board, partly due to both currency specificities and financial history. With this challenge of corporate governance in mind, an executive board should take a pedagogical approach, and formulate a 'philosophy' before implementing a currency-hedging strategy, even if, most of the questions remain unresolved. Academic debate (both economic theory and empirical studies) is, as always, a good starting point.

This paper will address two topics:

- First, what is the currency philosophy of a recently-established pension fund 
like the FRR? In other words, which major principles were considered before the currency overlay programme was implemented?

- Secondly, what is the currency overlay practice at the FRR?

Nevertheless, this paper adopts a humble tone as the overlay programme in the FRR has only recently started, and there is not yet the necessary track record to draw final conclusions.

\section{What is the FRR currency 'Philosophy'?}

Although most of the questions concerning the currency market remain unanswered, the following has been established:

- Unlike with stocks, bonds or private equity, there is no clear evidence that taking systematically long or short positions on currencies will be rewarded by a risk premium, even for emerging market currencies. This implies, first, that an investor must hedge a very large part of its international exposure. Secondly, it means that currency is a separate asset class in the sense that it is a tactical rather than a strategic asset class. Thus, currency is not accurate in a core-satellite approach, but has to be considered in an overlay way.

- The impact of currency hedging should be measured by comparing hedged and unhedged portfolio risk At some point, however, the marginal cost of hedging currency risk may exceed the marginal gain, suggesting that fully hedging may not be optimal. Furthermore, being fully and continuously hedged is unrealistic. Finally, targeting a 100 per cent hedge currency ratio risks over-hedging just after a market decline.
- There are inefficiencies in the currency market because not all participants are necessarily profit-driven. Central banks, for example, are active in the market to dampen volatility. Such behaviour can generate patterns in exchange rates and arbitrage opportunities. Thus, because some market participants may seek nonmonetary gains, active currency management makes sense for the long-term investor.

- Exchange rate evolution is a combination of:

- 'Fair price': purchasing power and interest parities are likely to prevail in the long term, or in certain volatile regimes. ${ }^{1}$

- Momentum: empirical evidence suggests that currency returns show positive autocorrelation over longer horizons. This is notably attributed to the herding behaviour of market participants and the self-fulfilling prophecy of trend, whereas there is a negative autocorrelation at a tick-by-tick level linked to microstructural features. More globally, inefficiencies in the currency market manifest in many different ways, such as mean-reversion, trending, volatility memory (clustering) etc.

- Central banks and political messages: for example, Figure 1 illustrates the fact that, in certain cases, central bank interventions on the forex and G7 statements may have a significant impact on market participants' perception.

- Risk factors: For example, International Monetary Market (IMM) positions, volatility regimes etc. In particular, risk is asymmetric when speculative positions are very short or long, or when volatility is unusually high.

Depending on how these factors are 


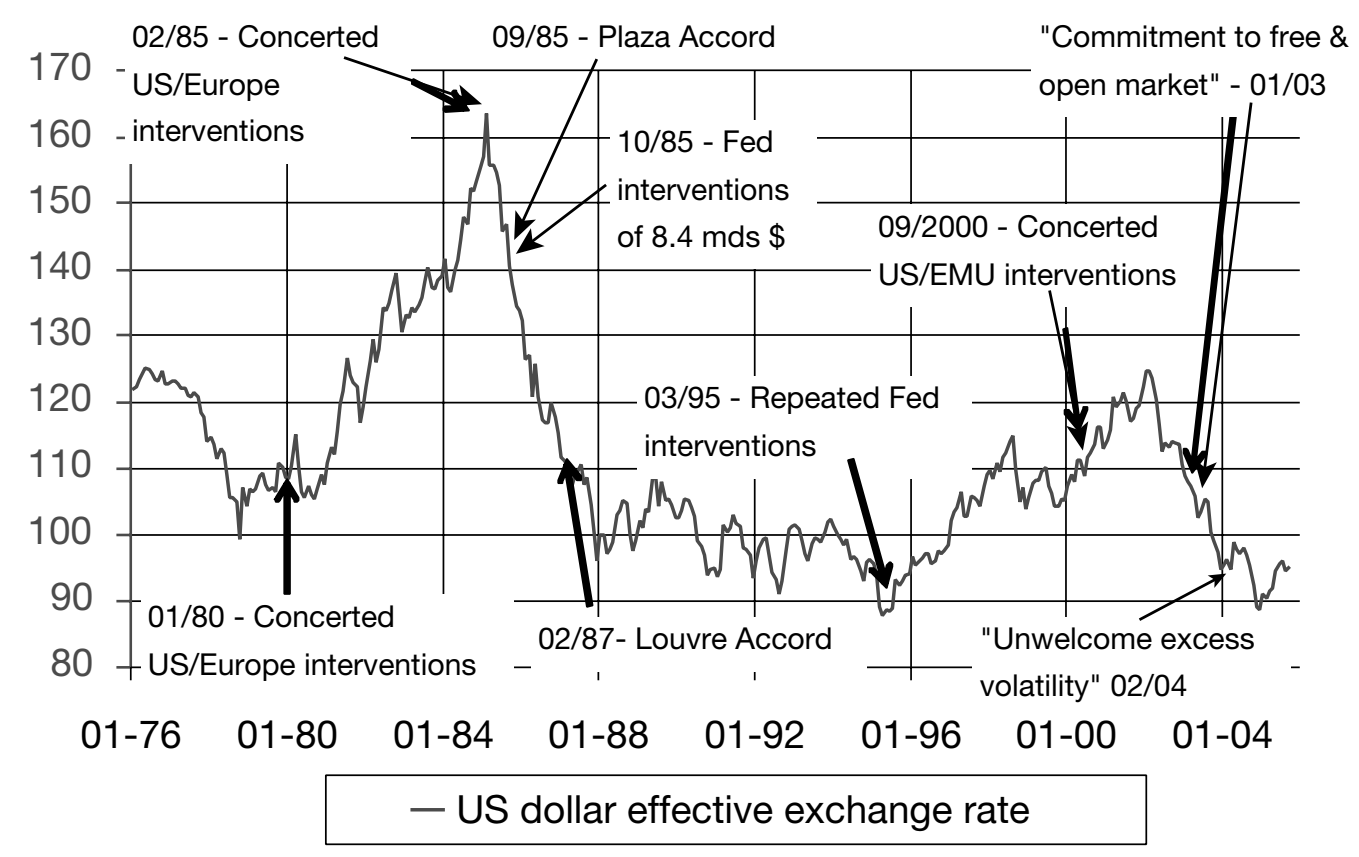

Figure 1: Dollar and political message Source: FRR

structured, one may be more or less comfortable with an investment process, whether it is an outsourced or an internal mandate. In other words, the way one interprets forex movements necessarily has implications on the investment process and the asset manager one selects.

The concept of currency overlay means different things to different people. FRR defines currency overlay as a process whereby currency risk is managed separately from all the underlying assets, by a specialist manager (or managers) with a dedicated risk budget. In theory, advantages are numerous: expected reward, clearer responsibility process, better performance measures and improved communication (which are crucial when considering pension fund governance challenges).

Nevertheless, in many sales pitches and published articles, currency overlay is presented as a magic means to earn extra returns for next to nothing. But there is no free lunch: no reward with zero risk. In Figure 2, the dotted line follows a normal distribution, representing the random walk view of currency returns. The solid line shows the shift in the distribution of currency returns that is the aim of an overlay programme: a hedge to large negative movements, a return profile skewed to the right but with an increased likelihood of small losses.

\section{Currency overlay practice at the FRR}

With this theoretical background in mind, many decisions — such as rebalancing frequency, adjustment bands or allowable tracking error — were made on practical grounds:

- Based on the FRR portfolio structure (24 per cent international assets, two-thirds in US\$, 11 currencies in the benchmark), on 


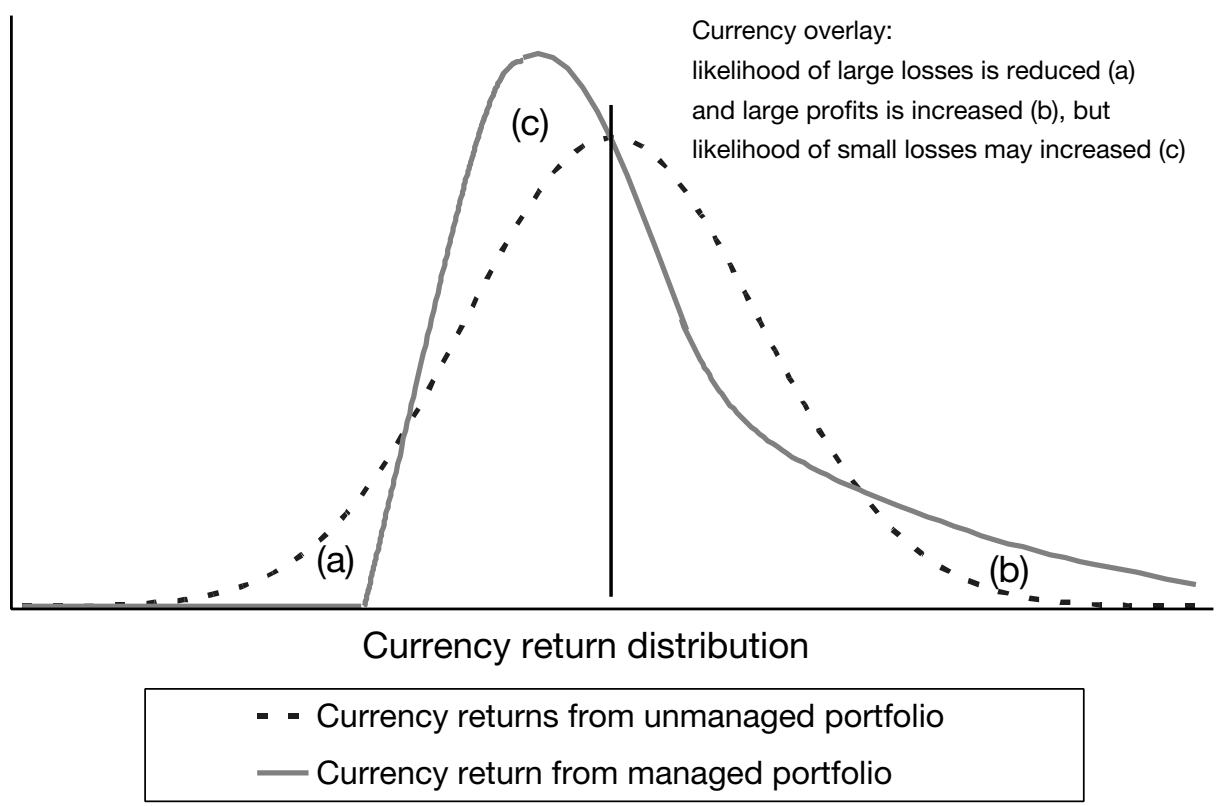

Figure 2: Payoff profile with and without currency overlay programme Source: Xin2

variance-covariance matrix and historical simulation, a 70 per cent hedge ratio (the hedge ratio is defined as the percentage of the notional amount of currency hedging with respect to the underlying exposure) would most likely have been sufficient to eliminate 80 per cent of the currency risk in the FRR portfolio. Nevertheless, the FRR's cautious approach (the risk aversion) induced the FRR to take a buffer with a minimum hedge ratio of 80 per cent (see Figure 3). If the FRR global hedging ratio is supposed to be between 80 and 100 per cent, single currencies can be from 0 to 100 per cent hedged.

- As the hedging currency policy is expressed in terms of margin (80-100 per cent), this means that the FRR strategic or passive hedge ratio is 90 per cent. So is the asset manager benchmark. Obviously, the type of active positions a currency overlay manager can take will depend on the passive hedge ratio. It is easy to see that, with a 90 per cent passive hedge ratio, a currency overlay manager has a symmetrical benchmark, meaning it can go either long or short depending on the manager's currency views. Typically, if the overlay manager expects a euro-dollar increase (euro appreciation), he hedges the dollar FRR exposure between 90 and 100 per cent; conversely, if a euro-dollar decline (euro depreciation) is forecast, he hedges the dollar FRR exposure between 80 and 90 per cent.

- Recalling that a typical asset management process opposes the portfolio (or the exposure) to the benchmark (which is the target in a passive mandate, or the performance standard in an active strategy):

- On the one hand, the Fund exposure valuation is greatly facilitated by there being a central custodian with weekly inflows. An intra-weekly estimation of this exposure may be then derived from 


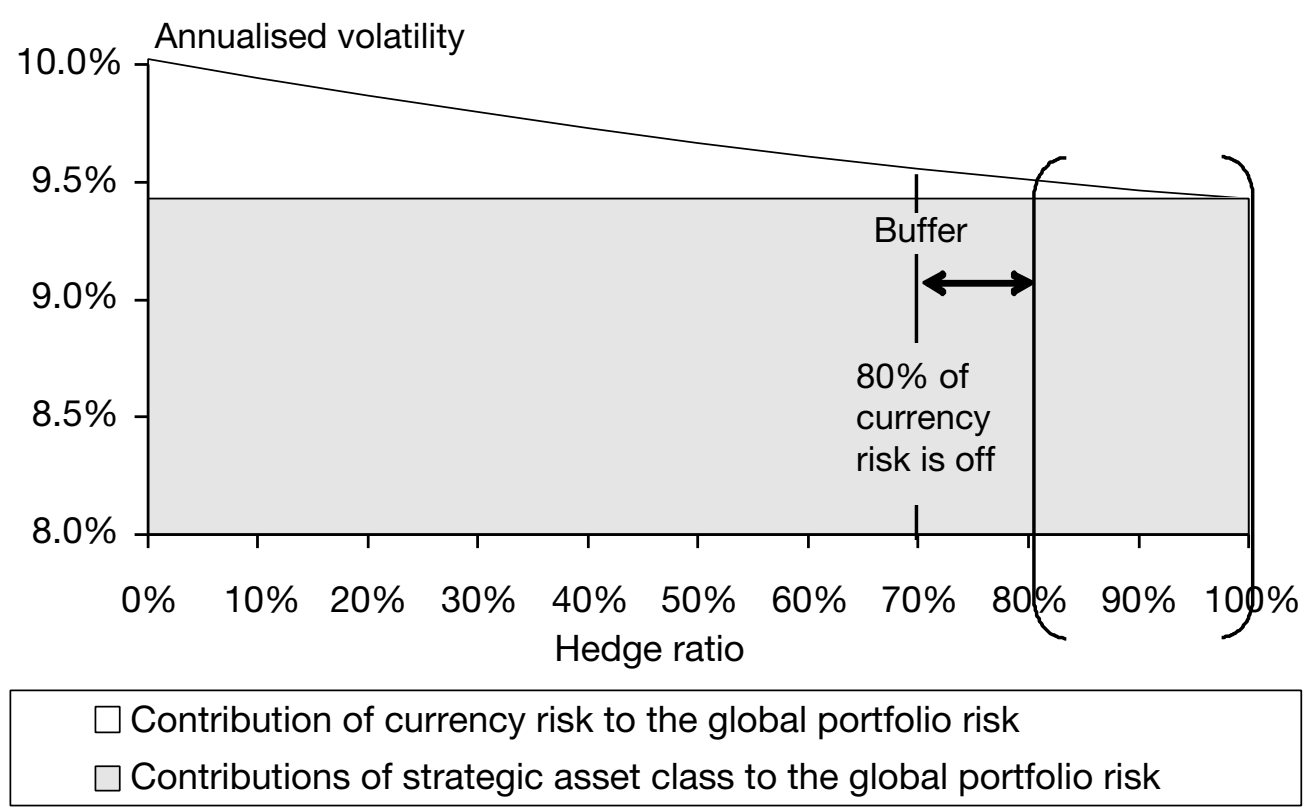

Figure 3: Estimated hedge currency impact on FRR risk profile Source: FRR

each asset class benchmark. Furthermore, the FRR has aggregated all the currency exposure coming from both physical and futures (Tactical Asset Allocation: TAA) investments.

- On the other hand, the FRR has to precisely specify the currency overlay manager target (or benchmark). Ex ante, it can be considered sensible to define the currency overlay benchmark as hedging 90 per cent of the estimated FRR international exposure. However, this approach is not 'purely' passive. Ultimately, if, say, there is zero Danish Krone (DKK) exposure in the FRR portfolio, an overlay benchmark consisting in hedging 90 per cent of the estimated DKK exposure means that there is no position on this currency in the overlay account. Hedging 90 per cent, however, means that 10 per cent of the exposure is unhedged, ie at risk.
Thus, a purely passive hedging policy implicitly assumes the FRR portfolio is necessarily sensitive to DKK for 10 per cent. In practical terms, the currency overlay target consists of hedging 100 per cent of the estimated exposure on a currency, and then to adjust this hedge to a residual obtained by multiplying the currency position in the FRR benchmark by 10 per cent. In this DKK example, this means that the overlay account should have a spot exposure. Obviously, the hedge need will be consolidated. In truth, this method is not much different from hedging 90 per cent of the estimated FRR international exposure, but it is supposed to be more rigorous.

- Concerning the choice of hedging horizon, the FRR has decided to retain a monthly hedge adjustment. In fact, as the TAA and rebalancing frequency processes are monthly (ie the FFR's positions are formally questioned 
on a monthly basis, but not necessarily changed), it makes sense in a homogeneous framework to have a monthly currency hedge rebalancing in addition.

- Currency overlay instruments are forwards with only two permanent three-month maturities (ie the roll frequency is twice per quarter). A credit agreement must be in place before the overlay manager can deal in currency forwards with a bank.

- An important practical question related to currency hedging is cash management, as profits/losses on currency hedges need to be settled in cash, whereas currency exposure does not crystallise until the underlying investment is sold. If not properly considered, this temporal mismatch may force a fund to (partially) liquidate investment positions. The target is to avoid investment liquidation both because it is too costly and the worst is never certain. The target is to calibrate the cash requirement for 'most' of the market situation. Thus, estimating the potential passive cash flow requirement is an exercise that closely resembles a value-at-risk calculation. This has been done using historical simulations.

Estimations were calculated taking into account the currency and tactical activities simultaneously: to benefit from diversification, it makes sense to consolidate the cash needs from forwards (currency overlay process) and from futures (the TAA process).

The simulations concluded that the cash requirement is probably in the region of 4-5 per cent of the portfolio net value. Due to the FRR's cautious approach, the target is 6 per cent with some stop-loss rules meaning that the FRR is ready to inject cash if the level falls towards a lower bound, and allocate cash to the underlying investment if the level moves towards the upper bound. This cautious approach has an opportunity cost, as an equitisation scheme has been implemented, meaning that part of the cash is re-invested in futures consistent with the FRR strategic allocation.

- The risk budget dedicated to currency overlay is a 25bp ex ante tracking error (TE) on a global portfolio basis (compared, for example, with a 100bp ex ante tracking error dedicated to TAA). The currency risk is monitored centrally via an arbitrage pricing theory environment.

- There are no general rules on whether or not a currency management should be outsourced. Financial theory suggests that internal managers can take on more risk than external managers because they are less likely to be replaced. ${ }^{3}$

However, as the FRR is a newly established pension fund with no specific competencies on currency, the investment process has been outsourced. Currency management is a specific job which should be held by a specialist. In 2004, the FRR implemented a formal process of searching for and selecting an overlay manager. This asset manager provides financial advice and implements tactical asset allocation decisions made by the Fund's executive board; the manager will also be responsible for hedging the currency risk.

Thus, the currency decision is functionally separated from the other decisions. Obviously, taking a separate decision is not equivalent to taking the decision separately: currency decisions can be made at the same time as decisions on other asset classes.

- Nevertheless, like other mandates, the manager selection process has not been outsourced. In terms of value added, the manager selection process is probably as important as the currency 
strategies. As the manager selection process is the direct responsibility of the pension fund, the executive board should justify any over or under-performance from an asset manager. The FRR philosophy on this point is to consider that the best way to successfully justify a performance to the supervisory board is to select the asset managers independently (although one can, of course, rely on consultants to analyse the manager's track record, for example). Due to the internal pension fund governance process, it is necessary to be completely comfortable with the investment process. In other words, it should fit with your own interpretation of forex, and it should not be a 'black box', otherwise, it would be difficult to fully justify your asset managers' decisions.

Beyond these principles, reality for a newly-established pension fund requires pragmatism when implementing a new architecture. In the case of the FRR, a two-step implementation was required:

- In order to control the operational risk during the investment process and mandate activation, it was decided to initially delay the active part of the overlay mandate, and to satisfy with a passive approach. In other words, the hedge ratio fixed at 90 per cent for each currency, is adjusted monthly against the underlying benchmark, but with some intra-monthly stop loss. Even if in a passive step, this does not imply a benign neglect to currency movements. For example, faced with 'obvious' asymmetric risk on a currency, the hedge ratio has been previously increased, then normalised back to 90 per cent as soon as the balance of risks is symmetric once more.

- In the second step, the active process of the currency overlay management will be started. Any deviation from 90 per cent will then be exclusively the overlay manager responsibility.

\section{Conclusion}

The currency overlay solution depends on asset-liability management (ALM) problems, portfolio structure, the governance process and the pension fund's track record; thus there is no unique solution. This implies that overlay managers should understand customer needs well and propose customised solutions. Institutional investors, on their side, have to be very pragmatic (pragmatic means, in some cases, modest), and develop pedagogic effort to their stakeholders (particularly the board and the fund contributors).

\section{References}

1 Huisman, R., Koedijk, K., Kool, C. and Nissen, F. (1998) 'Extreme support for uncovered interest parity', Journal of International Money and Finance, Vol. 17, No. 1, pp. 211-228.

2 Xin, H. (2003) 'Currency Overlay - A Practical Guide', Risk Books, London, UK.

3 Elton, E., Gruber, M. and Blake, C. (2003) 'Incentive fees and mutual funds', Journal of Finance, Vol. 58, No. 2, pp. 779-804. 